\title{
RADIAÇÃO ULTRAVIOLETA, OZÔNIO TOTAL E AEROSSÓIS NA CIDADE DE NATAL- RN
}

\author{
Alexandre Boleira Lopo ${ }^{1}$, Maria Helena Constantino Spyrides ${ }^{1}$, Paulo Sérgio Lucio ${ }^{1}$ e Javier Sigró ${ }^{2}$. \\ ${ }^{1}$ Universidade Federal do Rio Grande do Norte-UFRN, Programa de Pós-Graduação em Ciências \\ Climáticas-PPGCC. \\ ${ }^{2}$ Universidade Rovira i Virgili (Tarragona, Espanha), Centro de Mudanças Climáticas (C-3). \\ alexandrelopo@hotmail.com - spyrides@ccet.ufrn.br - pslucio@ccet.ufrn.br - javier.sigro@urv.cat
}

Artigo submetido em novembro/2013 e aceito em dezembro/2013

\section{RESUMO}

A cidade de Natal é denominada pelos seus habitantes de "Cidade do Sol" em razão de sua elevada luminosidade, contudo a capital do Rio Grande do Norte possui taxas de câncer de pele não melanoma acima da média das capitais do Nordeste do Brasil. Neste cenário, o presente artigo apresenta um estudo da radiação ultravioleta (UV) e índice UV em Natal e suas relações com variáveis relevantes como ozônio total, aerossóis, radiação solar global (RSG) e nebulosidade. A metodologia realizou um estudo descritivo e estatístico com aplicação da Análise de Componentes Principais (ACP) e Gráfico Biplot. Os dados foram obtidos no Instituto Nacional de Pesquisas Espaciais/Centro Regional do Nordeste (INPE/CRN), nos instrumentos TOMSOMI/AURA e MODIS/TERRA e no Instituto Nacional de Meteorologia do Brasil. Os resultados indicaram que o índice UV apresenta média anual igual a 11, classificado como extremo pela Organização Mundial de Saúde e a intensidade da UVB e índice UV no primeiro semestre do ano são mais intensos que no segundo. A variabilidade anual da UV possui uma característica nos meses de setembro e outubro que consiste em uma estabilização/redução do índice UV numa fase de crescimento da RSG em razão da maior concentração anual de ozônio total, sendo que a maior quantidade de aerossóis contribui em menor escala para este evento. A ACP e gráfico Biplot contribuíram para identificar o evento, pois indicaram que o ozônio total e aerossóis possuem uma forte correlação negativa com o índice UV nos referidos meses. Os autores chamaram esta característica de Evento Anual de Primavera da UV (EAP-UV), uma vez que ocorre no início e durante esta estação.

PALAVRAS-CHAVE: análise de componentes principais, espessura óptica de aerossóis, evento anual de primavera da UV, gráfico biplot, índice UV.

\section{ULTRAVIOLET RADIATION, TOTAL OZONE AND AEROSOLS IN CITY OF NATAL-RN}

\section{ABSTRACT}

The city of Natal is called by its inhabitants "Sun City" because of its high luminosity, however the capital of Rio Grande do Norte has rates of no melanoma skin cancer above the average of the capitals northeast of Brazil. In this scenario, article presents a study of the variability of Ultraviolet radiation (UV) and UV index for the city of Natal and its association with relevant variables as total ozone, aerosols, cloudiness and global solar radiation (RSG). The methodology conducted a descriptive study with statistical application of Principal Component Analysis (PCA) and Biplot graphic. The data were obtained from the National Institute of Spatial Research/Northeast Regional Center (INPE/CRN), instruments TOMS-OMI/AURA and MODIS/TERRA and National Institute of Meteorology of Brazil. The results indicated that the UV index has an
\end{abstract}

annual mean of 11 , rated as extreme by the World Health Organization and that intensity of UVB and UV index in the first half of the year are more intense than in the second. The annual variability of UV has a feature in the months of september and october that consisting of a stabilization/reduction of the UV index in a growth phase of RSG due to higher annual concentration of total ozone. The highest intensity of aerosols during this period contributes to this event. PCA and Biplot graphic contributed to identify the event, because indicated that total ozone and aerosols have a strong negative correlation with the UV index in those months. The authors called event with the abbreviation AES-UV (Annual Spring Event from UV) since it occurs at the beginning and during this season.

KEYWORDS: principal components, aerosol optical depth, annual spring event, biplot graphic, UV index. 


\section{RADIAÇÃO ULTRAVIOLETA, OZÔNIO TOTAL E AEROSSÓIS NA CIDADE DE NATAL-RN}

\section{INTRODUÇÃO}

A radiação ultravioleta (UV) é uma das radiações não ionizantes do espectro eletromagnético, sendo uma pequena parte do espectro solar, na ordem de $7 \%$ a $9 \%$ da radiação solar total incidente no topo da atmosfera terrestre ou aproximadamente $8 \%$ da constante solar. A UV é de grande importância na estruturação da atmosfera terrestre e tem grande ação na biosfera $[1,2]$.

A UV possui uma faixa espectral de comprimentos de onda $(\lambda)$ entre 100 e $400 \mathrm{~nm}$ e pode ser classificada de acordo com os efeitos à saúde humana e ao meio ambiente em: UVA, $315 \mathrm{~nm}$ a $400 \mathrm{~nm}$; UVB, $280 \mathrm{~nm}$ a $315 \mathrm{~nm}$ e UVC, 100 a $280 \mathrm{~nm}$ [3, 4]. A radiação na faixa UVC corresponde a cerca de $1 \%$ da emissão solar e não atinge a superfície terrestre devido à forte absorção na atmosfera pelo ozônio e oxigênio molecular, sendo importante na química da estratosfera e formação da camada de ozônio [1-4]. A radiação na faixa UVB é mais energética, correspondendo a 1,5\% da energia total do Sol, sendo $90 \%$ absorvida pelo ozônio, vapor de água, oxigênio e dióxido de carbono e apresenta o maior efeito biológico na superfície terrestre [1, 5, 6]. A radiação na faixa UVA compreende aproximadamente $6,3 \%$ da emissão da energia total do Sol $[1,6,7]$, sendo menos afetada pela atmosfera e, em consequência, a maior parte atinge o solo. O retroespalhamento por nuvens é a principal fonte de opacidade atmosférica nesta faixa $[3,8]$.

A faixa da UV (280 - $400 \mathrm{~nm})$ que atinge a superfície da Terra é afetada principalmente na atmosfera pela absorção de ozônio, nebulosidade, aerossóis e poluentes na troposfera e no solo pela refletividade, sendo composta por $90 \%$ da UVA e $10 \%$ da UVB $[4,6,8,9]$. A altura da superfície também influencia, medidas mostram um aumento da UV entre 6 a 8\% ou ainda maiores por quilômetro de elevação. Em lugares mais altos, a UV atravessa parcela menor da atmosfera e menor quantidade de elementos absorventes e dispersantes $[10,11]$.

Os aerossóis são uma suspensão de partículas líquidas ou sólidas em um gás cujo efeito direto na atmosfera é o espalhamento e absorção da radiação solar, inclusive a UV, e indiretamente alteram as propriedades das nuvens atuando nos núcleos de condensação [12, 13]. A quantidade de aerossóis na atmosfera pode ser observada por meio da espessura óptica de aerossóis, em inglês, aerosol optical depth (AOD). Este parâmetro é uma medida adimensional de extinção da radiação solar devido à interação com partículas de aerossóis na atmosfera [12 14].

O ozônio $\left(\mathrm{O}_{3}\right)$ é o maior responsável pelas oscilações da UV e seus impactos na natureza e saúde do ser humano $[1,3,15,16]$, sendo sua quantidade mensurada na atmosfera de forma vertical através da coluna total de ozônio ou ozônio total, sendo que as maiores concentrações estão na estratosfera, entre 20 e $25 \mathrm{~km}$ acima da superfície terrestre, diminuindo à medida que aumenta a altura $[4,9,17,18]$.

A formação do $\mathrm{O}_{3}$ na atmosfera é uma reação natural que acontece nas médias latitudes, quando uma molécula de $\mathrm{O}_{2}$ combina-se a um átomo livre de oxigênio [17], contudo sua distribuição na atmosfera não é homogênea devido à circulação dos trópicos para os polos gerando uma concentração maior de $\mathrm{O}_{3}$ nas altas latitudes com diminuição em direção ao equador [19]. Esta circulação acontece na estratosfera sendo denominada de Brewer-Dobson e se refere à movimentação de massas de ar que ascendem nos trópicos e descem nos polos, 
sendo controlada por processos de circulação complexos associados ao balanço de radiação na Terra, ondas planetárias e processos de subsidência no vórtice polar. Cada hemisfério apresenta uma circulação própria com diminutas transferências de ar entre eles $[9,19]$.

Na Região Nordeste do Brasil (NEB), onde está localizado o Rio Grande do Norte (RN), e sua capital (local desta pesquisa), pesquisas indicaram queda do ozônio total [20, 21], que no momento encontra-se em recuperação como resultado do Protocolo de Montreal, em vigor desde 1989 [4, 17], no entanto existem projeções de aumento da UV [21, 22] e elevação do valor médio do Fluxo de Radiação Ultravioleta (FUV) no Hemisfério Sul, inclusive no NEB (latitudes de $20^{\circ}$ a $0^{\circ}$ ) [21-23]. Esta região apresenta uma climatologia da UV ery (UV eritêmica ou biologicamente ativa) com valores considerados elevados [24].

Natal, capital do RN, é uma cidade turística de belas praias com elevada luminosidade solar (insolação e radiação solar) [25], sendo chamada pelos seus habitantes de "Cidade do Sol"

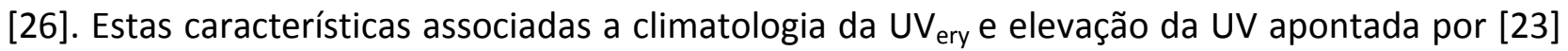
podem representar um aumento no número de casos de câncer de pele não melanoma (CPNM) nesta cidade, que inclusive apresenta taxas de CPNM acima da média regional em relação às demais capitais do NEB, sendo $54 \%$ superiores para as mulheres e $87 \%$ para os homens. Nas capitais do NEB, o CPNM entre os homens é o segundo tipo de câncer mais frequente $(34,69 / 100$ mil) e nas mulheres é o mais frequente $(31,17 / 100 \mathrm{mil})$. No Brasil, o CPMN é o de maior incidência e corresponde a aproximadamente $25 \%$ de todos os tumores [27].

A UV também exerce efeitos benéficos nas pessoas como a síntese e produção da vitamina $D_{3}$, fundamental para as funções osteoblástica e paratireóide [28] e vários efeitos sobre ecossistemas terrestres e aquáticos e materiais inorgânicos [3]. Apesar dos efeitos benéficos, é inequívoco que a exposição humana prolongada e sem critérios à UV pode resultar em efeitos nocivos, agudos e crônicos que se manifestam em doenças nos olhos e sistema imunológico [29, 30] e predominantemente sobre a pele através do envelhecimento precoce [31] e por meio de neoplasias, queimaduras e eritemas [3, 32], sendo as neoplasias de pele caracterizadas por aspectos diferentes de exposição ao sol: CPNM associada à exposição excessiva e acumulativa e o câncer de pele melanoma ou maligno (CPM), mais perigoso, relacionado aos episódios intensos e excessivos de exposição que resultam em queimaduras [32-34].

Para prevenção dos efeitos negativos à exposição inadequada e excessiva ao Sol e sensibilizar o público para este risco foi proposto pela Organização Mundial de Saúde (WHO, sigla em inglês) e Organização Mundial de Meteorologia (WMO, sigla em inglês) o Índice de Radiação Ultravioleta ou Índice Ultravioleta (índice UV ou IUV). O índice UV descreve a intensidade da UV na superfície do planeta, especialmente para uma condição de céu claro com ausência de nuvens. Este índice independe dos fatores fenotípicos, de modo que é universalmente usado por qualquer indivíduo da população, sem necessidade de considerar a cor da pele $[3,11,35]$.

Diante do apresentado, o presente artigo visa realizar um estudo na cidade de Natal da variabilidade da UV e índice UV em relação ao ozônio total, aerossóis, radiação solar global e nebulosidade.

\section{MATERIAIS E MÉTODOS}

\subsection{LOCAL DA PESQUISA}

Natal ( $5^{\circ} 48^{\prime}$ Sul e $35^{\circ} 12^{\prime}$ Oeste) é uma cidade litorânea do Atlântico Sul, localizada na costa leste do NEB, que possui 2.968,4 horas anuais de brilho solar (insolação total) [25], com uma 
trajetória do Sol que varia com inclinação de $65^{\circ}$ a $90^{\circ}$ [36] e radiação solar global horizontal de média anual próxima de 5,0 $\mathrm{kWhm}^{-2}$ [37]. A cidade possui clima tropical nordeste oriental (Figura 1 ), com temperatura do ar quente (média $\geq 18^{\circ} \mathrm{C}$ em todos os meses do ano) e semiúmida (4 a 5 meses secos) [38].

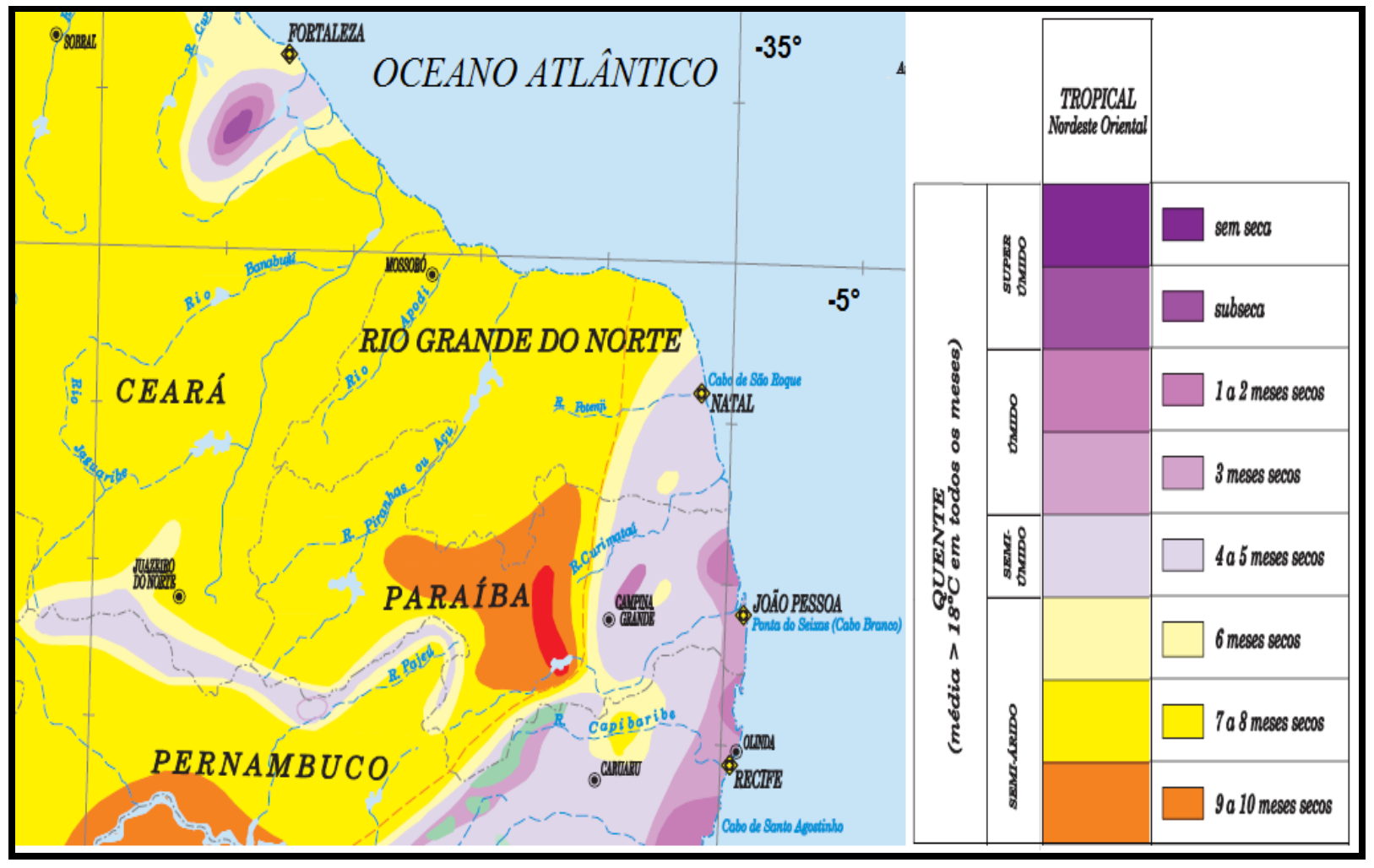

Figura 1. Clima do RN e de parte do Nordeste. Legenda mostra Clima Tropical Nordeste Oriental para a cidade de Natal. Fonte: Adaptado de Mapa de Clima do Brasil [38].

Em Natal, as médias anuais de temperatura e umidade relativa do ar são, respectivamente, $26^{\circ} \mathrm{C}$ e $77,3 \%$ [25]. A precipitação acumulada anual é de $1465,4 \mathrm{~mm}$ [25] influenciada pela proximidade do RN com a Zona de Convergência Intertropical (ZCIT) que recebe os ventos alísios. A estação chuvosa ocorre entre abril e julho, com predominância em abril (265 $\mathrm{mm})[25,39]$, em função das Ondas de Leste [40] e sistema de brisas do mar, resultante de diferenças de temperatura entre as superfícies terrestre e marinha. A precipitação aumenta durante a noite [41] e perturbações ondulatórias dos alísios, composta por massas de ar instáveis, profundas e úmidas causam chuvas rápidas e moderadas na região costeira do NEB com duração de até 48 horas e intervalos de 18-24 horas [40, 42, 43]. Os ventos mais fortes são característicos de setembro e os mais fracos ocorrem em abril [25]. Nesta cidade residem cerca de 850 mil habitantes em uma área de $17298 \mathrm{~km}^{2}$ [44].

\subsection{IRRADIÂNCIA ERITÊMICA E ÍNDICE UV}

A irradiância eritêmica é dada pela convolução entre a irradiância solar espectral da UV que atinge a pele e o espectro de referência de ação eritêmica (espectro biológico de ação) [35, 45].

O índice UV consiste de um fator de conversão da irradiância eritêmica e uma padronização numa escala numérica dividida em categorias associadas a cores (Tabela 1), que visa possibilitar uma rápida compreensão sobre a radiação ultravioleta biologicamente ativa. 0 
índice UV foi formulado (Equação 1) pela Comissão Internacional de lluminação (CIE- ISO 17166:1999 / CIE S007/E-1998) [3, 35]:

$\mathrm{IUV}=\mathbf{k}_{\mathrm{er}} \int_{250 \mathrm{~nm}}^{400 \mathrm{~nm}} \mathrm{E}(\lambda) \cdot S_{\mathrm{er}}(\lambda) \cdot d \lambda$

Em que: $\lambda$ representa o comprimento de onda em $\mathrm{nm} ; \mathrm{E}(\lambda)$ a irradiância solar espectral em $\mathrm{Wm}^{-2} \mathrm{~nm}^{-1} ; \mathrm{S}_{\mathrm{er}}(\lambda)$ a referência do espectro de ação eritêmica; $\mathrm{d} \lambda$ o intervalo de comprimento de onda utilizado na integral e; $k_{e r}$ uma constante igual a $40 \mathrm{~m}^{2} \mathrm{~W}^{-1}$. O índice UV igual a 1 representa $0,025 \mathrm{Wm}^{-2}$, indicando que cada ponto na escala é equivalente a $25 \mathrm{~mW}$ por metro quadrado de radiação UV $[22,35]$.

Tabela 1- Relação entre a faixa do índice UV e a categoria de risco para as pessoas.

\begin{tabular}{l|c|c}
\hline Categoria de risco & Faixa do índice UV & Cor \\
\hline Baixa & $0-2$ & Verde \\
Moderado & $3-5$ & Amarelo \\
Alto & $6-7$ & Laranja \\
Muito alto & $8-10$ & Vermelho \\
Extremo & $\geq 11$ & Violeta \\
\hline \multicolumn{2}{|c}{}
\end{tabular}

O índice UV diário é um número inteiro e adimensional que representa o máximo valor diário numa superfície horizontal [3, 35].

\subsection{DADOS}

\subsubsection{Irradiância espectral da UV e índice UV:}

Dados horários e diários (2001 a 2009) da Irradiância espectral da UV, em $\mu W \mathrm{~cm}^{-2} \mathrm{~nm}^{-1}$, foram mensurados na superfície pelo radiômetro multiespectral GUV (Ground-based Ultraviolet Radiometer), modelo 511-C, projetado para medir a radiação solar corrigida pelo cosseno do ângulo solar zenital, nos comprimentos de onda de $305 \pm 1 \mathrm{~nm}, 320 \pm 2 \mathrm{~nm}, 340 \pm 2 \mathrm{~nm}, 380 \pm 2$ $\mathrm{nm}$. Estas medidas foram integradas para converter em índice UV, de medida adimensional (ad), tal como definida pela CIE [46]. Os valores máximos diários foram coletados no intervalo entre 11 e 13h, independente das condições de céu.

O radiômetro GUV estava instalado (altitude de $58 \mathrm{~m}$ ) no Laboratório de Variáveis Ambientais Tropicais do Centro Regional do Nordeste do Instituto Nacional de Pesquisas Espaciais (INPE/CRN/LAVAT) localizado em Natal, sendo transferido para o interior do RN, limitando o estudo ao ano de 2009. As medições do índice UV continuaram com instrumento de banda larga (dados não utilizados nesse estudo). Os dados do índice UV do período de 2010 a 2012 foram obtidos na Estação Meteorológica (Modelo Davis com Sensor UV-6490) do Laboratório de Máquinas Hidráulicas e Energia Solar do Centro de Tecnologia da Universidade Federal do Rio Grande do Norte (UFRN/LMHES). Os dados foram coletados no intervalo de 11 $13 \mathrm{~h}$ na altitude de $60 \mathrm{~m}$ e estão entre 0 a 16 com $5 \%$ de incerteza.

Há agentes na atmosfera que influenciam a variabilidade da UV, assim foram selecionadas as variáveis a seguir e os dados foram obtidos em diversos instrumentos/fontes.

\subsubsection{Ozônio total ou coluna total de Ozônio:}


Dados diários (2001 a 2009) dos instrumentos TOMS (Total Mapping Spectrometer Ozone) e OMI (Ozone Monitoring Instrument) instalados em satélites da NASA/EUA (National Aeronautics and Space Administration) e disponibilizados pelo Goddard Earth Sciences Data and Information Services Center [47, 48]. Dados em Unidades Dobson (UD), em que 1 UD equivale a $2,69.10^{16}$ moléculas. $\mathrm{cm}^{-2}$. Em condições padrões de temperatura $\left(0^{\circ} \mathrm{C}\right)$ e pressão $(101,35 \mathrm{kPa}), 1$ UD equivale a $0,01 \mathrm{~mm}$ de espessura ou $100 \mathrm{UD} \approx 1 \mathrm{~mm}$ [49].

\subsubsection{Radiação solar global (RSG):}

Dados diários (2007 a 2009) mensurados pelo sensor/radiômetro de fabricante Kipp\&Zonen, modelo CM11-058912, instalado na Estação Solarimétrica do INPE/CRN/LAVAT [50]. Os dados em $\mathrm{Wm}^{-2}$ representam o valor máximo no intervalo de $11-12 \mathrm{~h}$.

\subsubsection{Nebulosidade e vento (intensidade e direção predominante):}

Dados diários (2001 a 2009) de nebulosidade às $12 \mathrm{~h}$ (escala de 0 a 10) e intensidade ou velocidade do vento $\left(\mathrm{ms}^{-1}\right)$ e as Normais Climatológicas da direção predominante do vento em graus $\left({ }^{\circ}\right.$ ) obtidas no Banco de Dados Meteorológicos para Ensino e Pesquisa do Instituto Nacional de Meteorologia do Brasil (INMET/BDMEP )[25, 51].

\subsubsection{Espessura óptica de aerossol (AOD):}

Dados diários (2004 - 2009) e adimensionais no comprimento de onda $550 \mathrm{~nm}$ coletadas pelo instrumento MODIS (Moderate Resolution Imaging Spectroradiometer) a bordo do satélite AQUA/NASA obtidas do Sistema de Informações Ambientais da Divisão de Satélites Ambientais do Centro de Previsão de Tempo e Estudos Climáticos (INPE/CPTEC/SISAM) [52].

\subsection{ANÁLISE ESTATÍSTICA}

A análise estatística consistiu do cálculo das medidas de posição e dispersão das variáveis (médias horárias, mensais, semestrais e anuais), elaboração de gráficos de linha e boxplot, filtragem de médias móveis, análise de componentes principais (ACP) com a construção do gráfico Biplot.

A ACP é uma técnica multivariada de redução de dados na qual o objetivo principal é a construção de uma combinação linear das variáveis originais gerando novas componentes ortogonais que representam e captam a variabilidade do conjunto original de variáveis. Este método foi utilizado com o objetivo de reduzir o número de variáveis gerando novas componentes captando as dependências entre as variáveis [53, 54], buscando assim uma relação natural, com análise de independência ou dependência, entre o índice UV e as variáveis: ozônio total, aerossóis (AOD), vento (intensidade), radiação solar global e nebulosidade.

A ACP consiste no cálculo dos autovalores e respectivos autovetores de uma matriz de variâncias e covariâncias ou de uma matriz de coeficientes de correlação entre variáveis. Sendo esta última matriz mais adequada ao presente estudo em função das unidades de medidas desiguais e da variância apresentar grande diferença entre as variáveis [53-55]. Sua aplicação ocorre por meio de uma transformação linear de " $m$ " variáveis originais em " $n$ " novas variáveis, de modo que a primeira nova variável (1 1 a componente) seja responsável pela maior variação existente no conjunto de dados, e assim por diante, até que toda a variação do conjunto tenha sido captada [54, 55]. A ACP está disponível em diversos softwares estatísticos, sendo utilizado para os cálculos o software estatístico R de acesso livre [56]. 
O gráfico Biplot ilustra a composição das duas primeiras componentes compreendendo as variáveis originais. Este gráfico representa as projeções das variáveis originais sobre os novos eixos, de modo que o cosseno do ângulo entre os vetores que representam as variáveis originais se aproximam do valor da correlação entre essas variáveis. A qualidade da representação obtida depende da proporção da variância explicada pelas componentes principais utilizadas [57].

\section{RESULTADOS E DISCUSSÕES}

\subsection{Irradiância espectral da UV}

A Irradiância está relacionada à variação da potência recebida e consiste do fluxo radiante incidente por unidade de área a partir de uma superfície $[2,35]$. As médias mensais, semestrais (1오 e 2ㅇ) e anuais da Irradiância espectral da UV nos comprimentos de onda $305 \mathrm{~nm}$ (UVB), 320 $\mathrm{nm}, 340 \mathrm{~nm}$ e $380 \mathrm{~nm}$ (UVA) mensuradas em $\mu \mathrm{Wcm}^{-2} \mathrm{~nm}^{-1}$ pelo radiômetro GUV estão indicadas na Tabela 2.

Tabela 2. Irradiância da UV por canal espectral na cidade de Natal-RN (2001-2009).

\begin{tabular}{l|r|r|r|r|r|r|r|r|r|r|r|r|r|r|r}
\hline$\lambda(\mathrm{nm})$ & Jan & Fev & Mar & Abr & Mai & Jun & Jul & Ago & Set & Out & Nov & Dez & 1 os & 2 oS & Ano \\
\hline 305 & 8,3 & 9,2 & 9,0 & 8,1 & 6,9 & 6,0 & 6,0 & 6,8 & 7,3 & 8,3 & 8,3 & 8,0 & 7,9 & 7,4 & 7,7 \\
320 & 36,2 & 38,3 & 38,0 & 34,9 & 31,1 & 27,9 & 28,9 & 32,4 & 34,5 & 37,4 & 37,9 & 36,1 & 34,4 & 34,5 & 34,4 \\
340 & 63,4 & 66,3 & 65,5 & 60,3 & 53,7 & 50,9 & 52,0 & 57,1 & 59,7 & 66,0 & 65,7 & 63,8 & 60,0 & 60,7 & 60,4 \\
380 & 85,2 & 88,9 & 87,9 & 81,0 & 73,9 & 70,2 & 71,4 & 77,9 & 82,3 & 88,3 & 87,9 & 85,6 & 81,2 & 82,2 & 81,7 \\
\hline
\end{tabular}

A Irradiância espectral da UV (Tabela 2 e Figura 2) se intensifica com o aumento do comprimento de onda, fato em concordância com a distribuição espectral da irradiância UV e Lei de Planck $[2,35,58]$. A variabilidade mensal desta variável pode ser observada na Figura $2 \mathrm{~B}$.
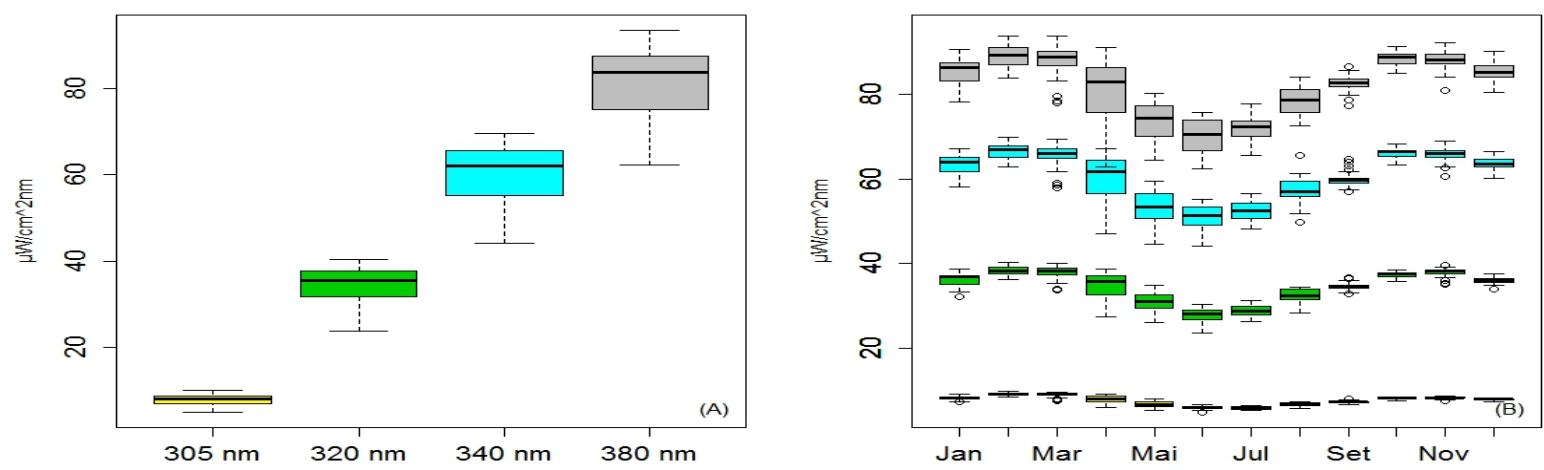

Figura 2. (A) Média da irradiância espectral da UV e (B) variabilidade mensal da UV em UVB (305 nm) e UVA (320 $\mathrm{nm}, 340 \mathrm{~nm}$ e $380 \mathrm{~nm}$ ) na cidade de Natal.

Conforme a Tabela 2, a UVB (305 nm) apresenta redução de 6,3\% na irradiância média do

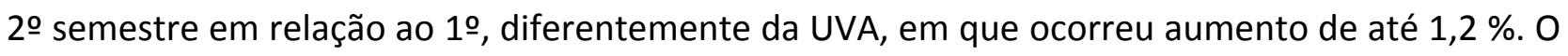
ozônio absorve fortemente a UVB e no 2o semestre acontece uma elevação do ozônio total (Figura 5B) e por consequência há um menor nível de UVB neste período. A filtragem de médias móveis da irradiância da UV por comprimento de onda (Figura 3) mostra esta redução e assim 
inferiu-se que a UVB é maior no 1 을 semestre do ano na cidade de Natal, incluindo-se o índice UV, conforme as médias semestrais (Tabela 3).
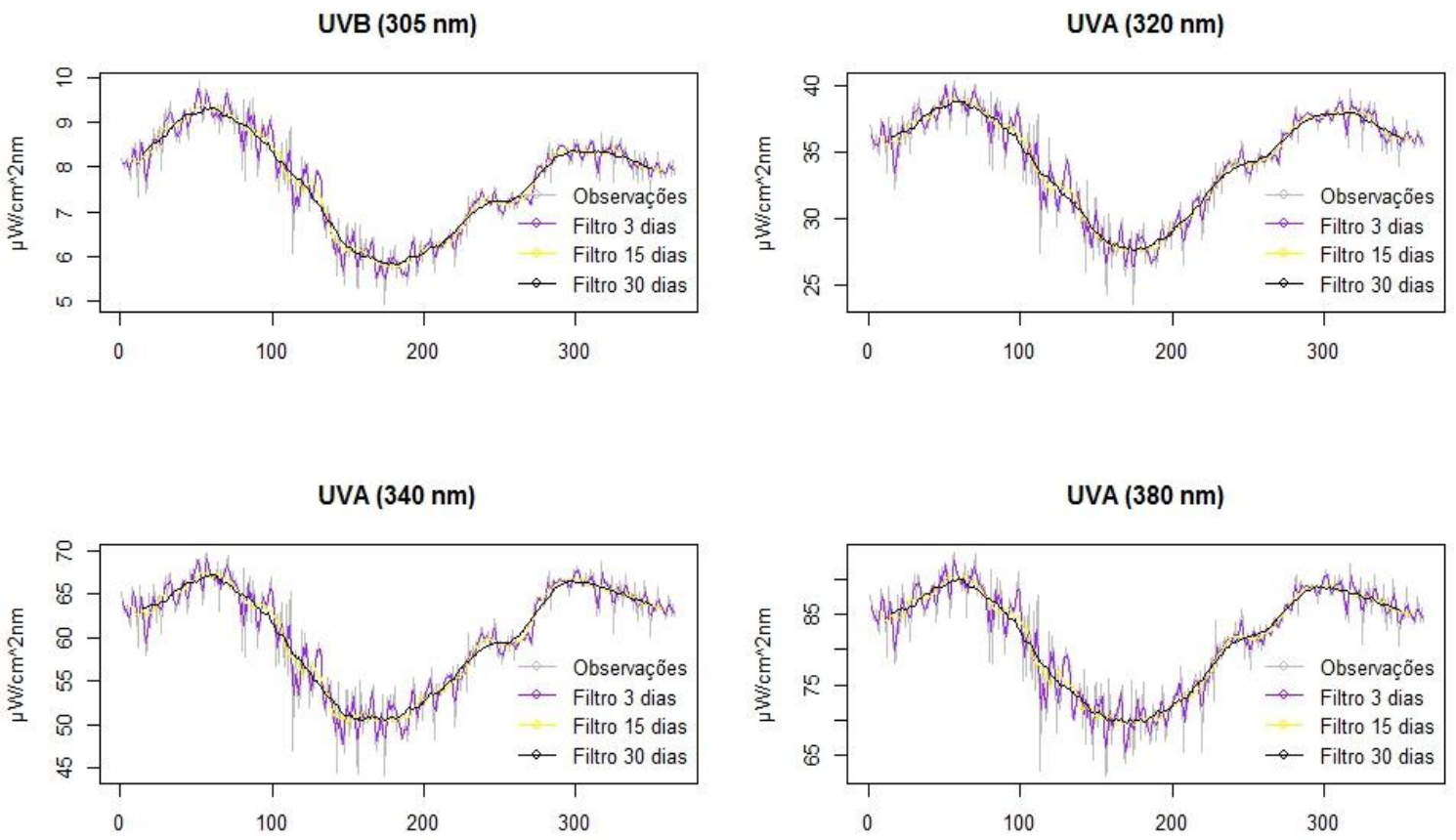

Figura 3. Irradiância espectral anual de UV, através de filtragem de médias móveis, em UVB (305 nm) e UVA (320 $\mathrm{nm}, 340 \mathrm{~nm}$ e $380 \mathrm{~nm}$ ) na cidade de Natal.

A Figura 3 mostra, além da redução da UVB no $2^{\circ}$ semestre, que acontece nos meses de setembro e outubro (dias 244 a 304) uma estabilização/redução da irradiância espectral da UV em todos os comprimentos de onda, em função dos máximos de ozônio total neste período (Tabela 3). Este evento será mais detalhado na análise do índice UV.

\subsection{Variabilidade do índice UV}

O ciclo diário do índice UV (Figura 4), considerando o período de um ano, atingiu às $8 \mathrm{~h}$ (horário local), índices categorizados pela WMO de risco "moderado" e "alto". No horário das $9 \mathrm{~h}$ alcança risco "alto" e "muito alto". O índice atinge valores de risco "muito alto" e "extremo" entre 10 e $12 \mathrm{~h}$, com predominância de risco "extremo" no intervalo 11 - $12 \mathrm{~h}$. A partir das $13 \mathrm{~h}$ os índices diminuem para risco "muito alto" e "alto", às $14 \mathrm{~h}$ para "alto" e "moderado" e às $15 \mathrm{~h}$ para "baixo" até o fim da tarde. Os valores são similares ao encontrado por [59].

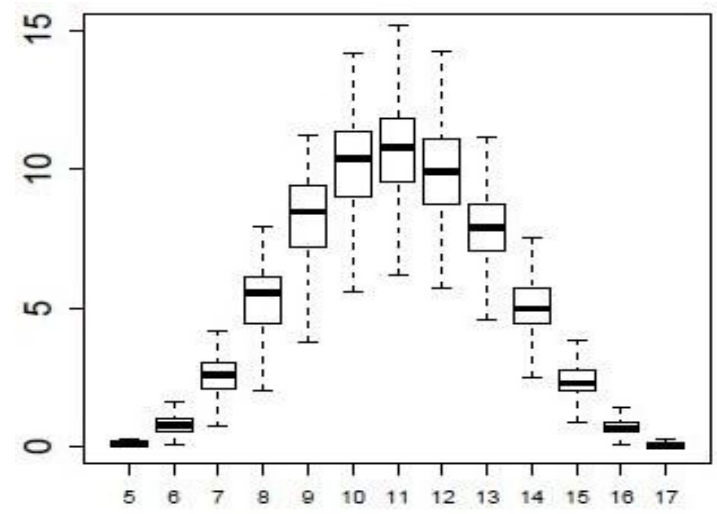

Figura 4. Boxplot do ciclo diário do índice UV no horário local (fuso horário UTC-3) para a cidade de Natal-RN (ano base 2008). 
O índice UV apresenta média anual igual a 11, valor considerado "extremo" pela WMO e muito próximo do encontrado por [59], alcançando esta classificação (cor violeta) em sete meses do ano (Figura 5A), predominantemente entre a primavera e verão. Nos meses de junho e julho ocorreram os menores índices, próximos a 9, ainda considerados como "muito altos" (cor vermelha).

Em termos sazonais, a média do índice UV é igual a 12 no verão, 10,6 no outono, 9,6 no inverno e 11,4 na primavera, sendo classificado como "extremo" em $80 \%$ dos valores diários do verão, $73 \%$ da primavera, $46 \%$ de outono, $17 \%$ do inverno e $54 \%$ considerando o período de um ano. No inverno $72 \%$ dos valores diários estão entre 8 e 10 , considerado de risco "muito alto".

\subsection{Influência na UV das variáveis estudadas.}

As médias mensais, semestrais (1오 e 2 으) e anuais do índice UV e das variáveis consideradas relevantes para análise da variabilidade da UV estão indicadas na Tabela 3.

A variabilidade da RSG apresenta uma associação direta com a variabilidade da UV, em razão desta última ser fração da radiação solar [1, 35]. A RSG consiste na energia do Sol na superfície da Terra, estando diretamente influenciada pelo ângulo solar zenital ou ângulo zenital (Z), ou seja, o ângulo formado entre o Zênite local e os raios solares [60]. A RSG é formada pela radiação solar difusa e direta. A radiação solar direta atinge a terra sem qualquer mudança de direção e a radiação solar difusa é resultante do espalhamento da atmosfera e atinge o local considerado após ter sofrido um ou mais desvios $[35,60]$.

Tabela 3. Médias mensais das variáveis climáticas em Natal-RN.

\begin{tabular}{|c|c|c|c|c|c|c|c|}
\hline Período & $\begin{array}{l}\text { Índice } \\
\text { UV }\end{array}$ & $\begin{array}{c}\text { Ozônio } \\
\text { total }\end{array}$ & $\begin{array}{c}\text { Aerossóis } \\
\text { (AOD) } \\
(550 \mathrm{~nm})\end{array}$ & $\begin{array}{r}\text { Ven } \\
\text { (intensic } \\
\text { direç }\end{array}$ & & $\begin{array}{c}\text { RSG- } \\
\text { Radiação } \\
\text { solar } \\
\text { global }\end{array}$ & $\begin{array}{c}\text { Nebulosidade } \\
\qquad(12 \mathrm{~h})\end{array}$ \\
\hline Unidades $\rightarrow$ & ad & UD & $\mathrm{ad}$ & $\mathrm{ms}^{-1}$ & $\left({ }^{\circ}\right)$ & $\mathrm{Wm}^{-2}$ & (0 a 10) \\
\hline Janeiro & 11,7 & 260,9 & 0,19 & 4,3 & 117 & 931,1 & 8,2 \\
\hline Fevereiro & 12,6 & 260,7 & 0,20 & 4,1 & 121 & 960,1 & 8,2 \\
\hline Março & 12,5 & 263,6 & 0,21 & 3,6 & 122 & 928,7 & 8,1 \\
\hline Abril & 11,3 & 260,7 & 0,16 & 3,5 & 135 & 748,4 & 8,3 \\
\hline Maio & 10,9 & 257,2 & 0,18 & 3,6 & 146 & 652,1 & 7,8 \\
\hline Junho & 8,7 & 259,4 & 0,15 & 3,6 & 149 & 542,3 & 8,0 \\
\hline Julho & 8,7 & 265,7 & 0,18 & 4,2 & 152 & 568,7 & 7,6 \\
\hline Agosto & 10,0 & 270,8 & 0,20 & 4,6 & 145 & 650,5 & 7,7 \\
\hline Setembro & 10,4 & 278,5 & 0,22 & 5,1 & 136 & 785,5 & 7,5 \\
\hline Outubro & 11,8 & 276,0 & 0,18 & 5,0 & 124 & 976,9 & 7,4 \\
\hline Novembro & 11,9 & 268,9 & 0,15 & 4,7 & 118 & 994,1 & 7,4 \\
\hline Dezembro & 11,3 & 262,2 & 0,17 & 4,6 & 115 & 972,1 & 7,8 \\
\hline 1ㅇosem. & 11,3 & 260,4 & 0,20 & 3,8 & 132 & 793,8 & 8,1 \\
\hline 2ㅇosem. & 10,7 & 270,4 & 0,20 & 4,7 & 132 & 824,6 & 7,6 \\
\hline Anual & 11,0 & 265,4 & 0,18 & 4,3 & 132 & 809,2 & 7,8 \\
\hline
\end{tabular}


A variabilidade da RSG na cidade de Natal apresenta valores próximos de $0,8 \mathrm{kWm}^{-2}$ no inverno e outono, atingindo no verão e primavera $1,0 \mathrm{kWm}^{-2}$ (Tabela 3 e Figura $5 \mathrm{C}$ ). A amplitude sazonal é pequena devido a proximidade com o equador (baixa latitude). Entre o equador e o trópico de capricórnio, em razão do Sol atingir duas vezes por ano o máximo ângulo zenital, ou seja, aproximadamente $0^{\circ}\left(Z \approx 0^{\circ}\right)$, as estações de observações registram dois máximos anuais de radiação solar, no verão, em fevereiro, na primavera, em outubro [61]. Esta característica foi observada em Natal, significando índice UV com máximos anuais em fevereiro $(\approx 13)$ e outubro $(\approx$ 12) (Tabela 3).

Os menores níveis anuais do índice UV são observados nos meses de junho e julho e correspondem aos valores mais baixos da RSG e próximos de $0,55 \mathrm{kWm}^{-2}$ (Tabela 3).
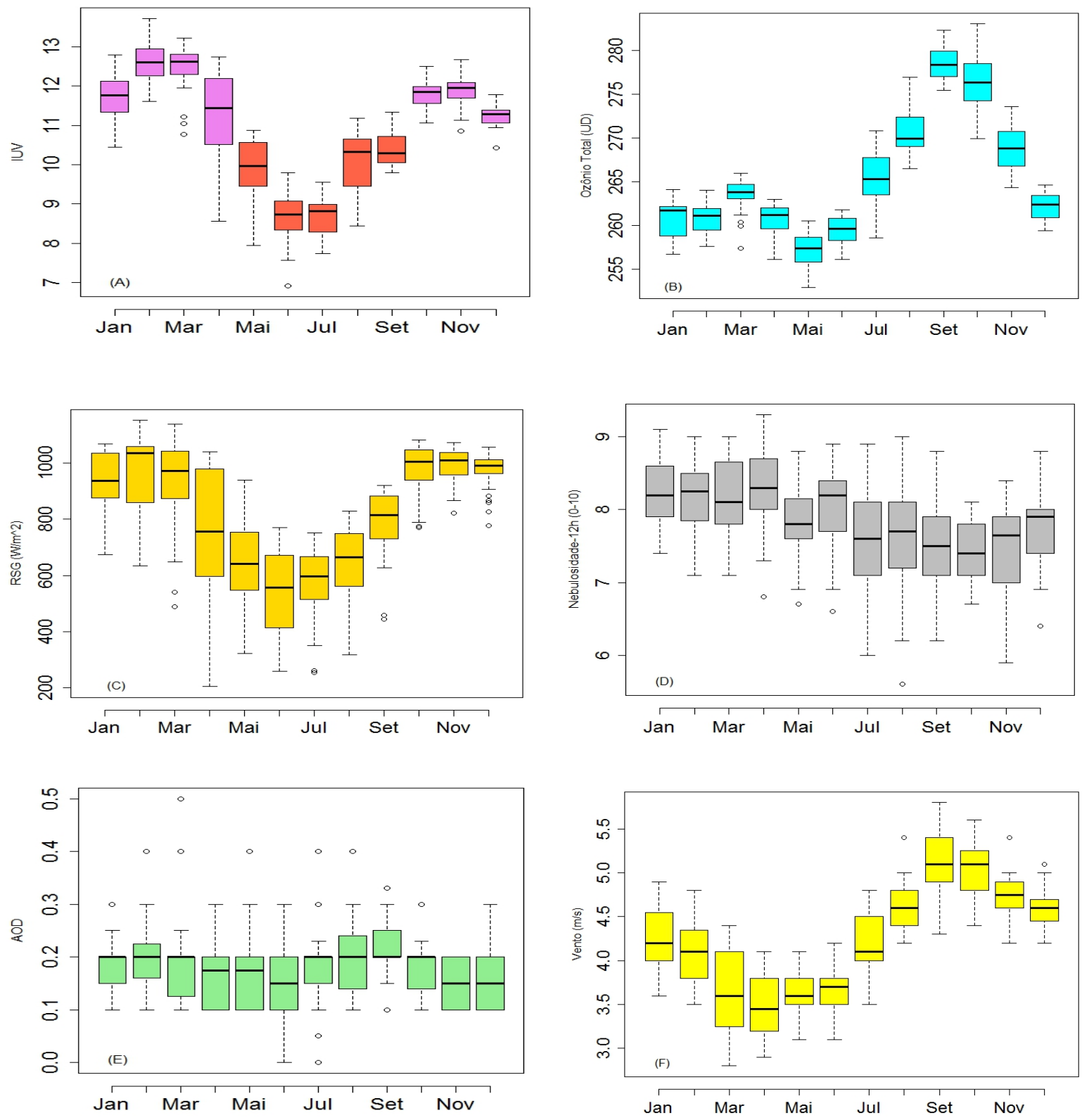

Figura 5. Boxplot da variabilidade do: índice UV (A); ozônio total (B); RSG (C); Nebulosidade às 12h (D); aerossóis (AOD) (E); e Vento (F) na cidade de Natal-RN. 
A nebulosidade foi analisada em função de atenuar por espalhamento e absorção a RSG e UV, especialmente UVA, causando grande variabilidade intradiária associada com as condições de cobertura de nuvens [8, 22]. Uma alta variância do índice UV (Figura 5A) e da RSG (Figura 5C) ocorreu em abril proporcionada pela maior presença de nuvens (Figura 5D) e maior precipitação $(265 \mathrm{~mm})$ que acontece no primeiro mês da estação chuvosa (abril - julho) na cidade de Natal $[25,39]$.

O índice UV (Figura 5A) atinge em fevereiro o máximo valor do 10 semestre com redução gradativa até junho. Em agosto, no início do 20 semestre, ocorre aumento do índice UV acompanhando o crescimento da RSG (Figura 5C), no entanto nos meses de setembro e outubro acontece uma estabilização/redução do índice, com destaque para setembro, no qual o índice UV permanece muito próximo do registrado em agosto. Esta característica está associada ao máximo de ozônio total nos referidos meses (valores em destaque na Tabela 3 e Figura 5B) e também foi observada por meio dos dados do UFRN/LMHES (Figura 6A e 6B).
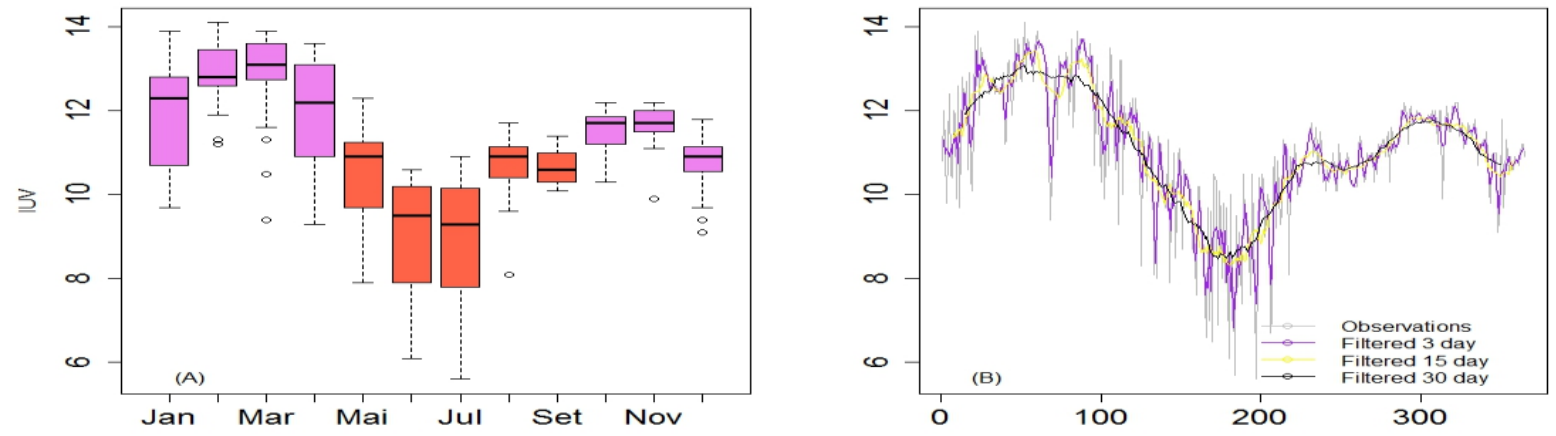

Figura 6. (A) Boxplot da variabilidade mensal (A) e filtragem de médias móveis (B) referentes ao índice UV na cidade de Natal-RN (2010-2012). Fonte: LMHES/UFRN.

A variabilidade do índice UV e ozônio total analisada simultaneamente e através de uma filtragem de médias móveis (destaque na Figura 7) mostra uma estabilização/redução do índice UV que acontece no momento do máximo valor anual de ozônio total. Não se encontrou a descrição desta característica na literatura científica e assim os autores denominaram de evento anual de primavera da UV (EAP-UV), visto que ocorre no ínicio e durante esta estação.

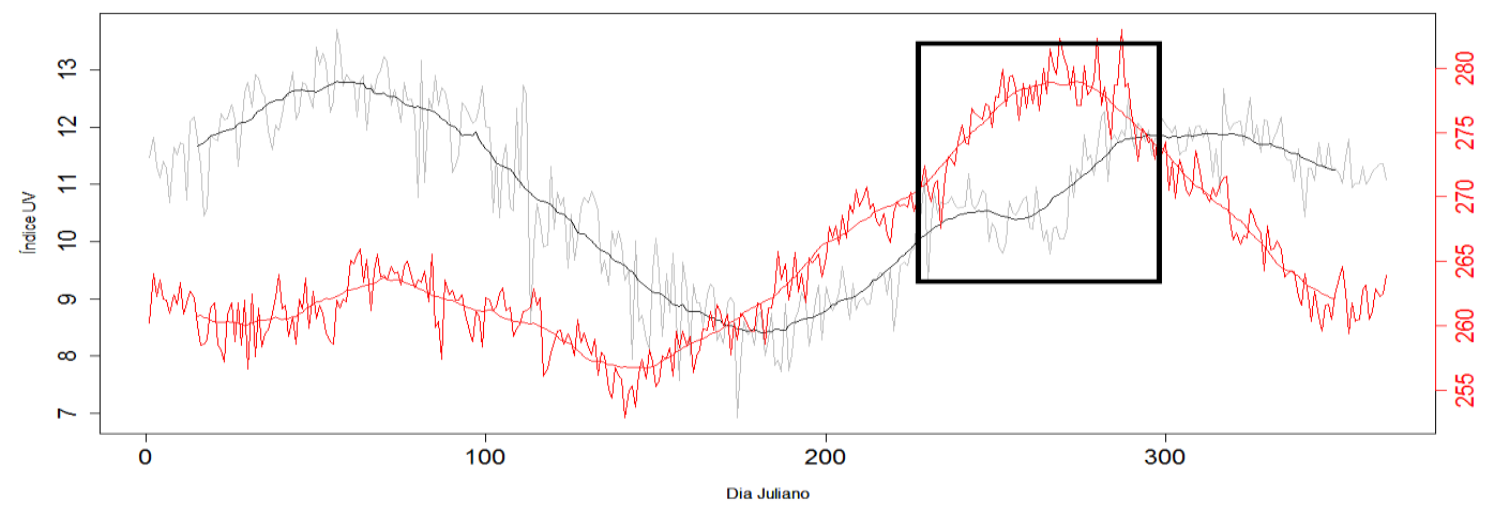

Figura 7- Gráfico (simultâneo e com filtragem de médias móveis e) da variabilidade anual do índice UV e ozônio total (vermelho e escala no lado direito) na cidade de Natal. 
O EAP-UV é melhor analisado em equinócios de outono (março) e primavera (setembro) no Hemisfério Sul, quando ocorre uma idêntica elevação do Sol e valores muito similares de RSG [62]. Isso permite comparar as oscilações do UV em relação ao ozônio total, que apresentou entre os equinócios uma diferença próxima de 15 UD ( $\operatorname{março~}=263,6$ UD e setembro $=278,5$ UD), representando na superfície duas unidades do Índice UV (março $=12,5$ e setembro $=10,4$ ) e uma alteração na classificação de "extremo" para "muito alto" e redução no risco às pessoas da exposição aos raios solares.

As fases de crescimento e decaimento do ozônio total (Figura 5B) estão associadas ao aumento de temperatura na atmosfera provocada pela absorção de radiação solar que gera instabilidades no equilíbrio fotoquímico da estratosfera, cuja região é responsável por cerca de $90 \%$ do ozônio, proporcionando uma queda da sua produção. Deste modo o teor máximo de ozônio é observado na primavera, no verão diminui e novamente aumenta no outono [9, 63, 64]. Ressalta-se que a média anual de ozônio total de 265,4 UD obtida neste estudo está abaixo de pesquisas anteriores que indicaram uma média anual de 275 UD [64] e 268 UD [65].

Em novembro, mês seguinte ao EAP-UV, houve aumento do índice UV em razão da elevação da RSG e queda do ozônio total. Para dezembro, apesar da redução do ozônio total, acontece uma diminuição do índice UV em correspondência à queda da RSG (Tabela 3 e Figura 5), fato observado através de medições em outros locais no Hemisfério Sul [5, 20,64].

Além do ozônio total, os aerossóis exercem uma influência no EAP-UV, em razão da sua maior presença em setembro, indicada pela AOD (Tabela 3 e Figura 5E). Pesquisas [14, 35, 66, 67] indicam que os aerossóis atmosféricos proporcionam diminuição do índice UV nos horários de máxima intensidade e que o aumento na concentração de aerossol devido à poluição e queimadas pode reduzir a UV.

Em Natal, o aumento de aerossóis em setembro está relacionado com a maior velocidade do vento e direção predominante de Sudeste (Tabela 3 e Figura 5F). A direção predominante, entre $120^{\circ}$ e $140^{\circ}$, indica vento do mar para o continente e explica a maior presença de aerossóis do tipo marítimo ou marinho, proveniente do Oceano Atlântico. O aerossol do tipo marítimo tropical possui baixa densidade de substâncias solúveis e componentes salinas e assume-se com ventos fracos $\left(\approx 5,0 \mathrm{~ms}^{-1}\right)[35,68]$. A análise sobre o tipo de aerossol é baseada em estudos anteriores que mostram atenuação típica exercida por partículas de tipo marítimo tropical [35]. Para este estudo não houve avaliação físico-química de material coletado.

Ressalta-se que as variações exercidas pelos aerossóis sobre a UV são menores do que aquelas relativas às variações do ozônio total, visto que os aerossóis marítimos apresentam transmitância média em torno de $95 \%$ para a UV [35, 68].

\subsection{ANÁLISE DE COMPONENTES PRINCIPAIS (ACP) E GRÁFICO BIPLOT.}

A ACP foi utilizada visando encontrar entre as variáveis atmosféricas abordadas as que mais se correlacionavam com o índice UV durante o EAP-UV, ou seja, durante os meses de setembro e outubro. A primeira etapa da ACP ocorreu com a padronização das variáveis, devido às diferenças entre as unidades de medidas, e o cálculo da matriz de correlação (Tabela 4) e dos autovalores e autovetores. 
O método da ACP gerou novas variáveis chamadas componentes principais, ortogonais ou não correlacionadas, seguida das correlações das variáveis e variação captada em cada componente resultante (Tabela 5). A primeira componente principal (CP1) representa as variáveis: índice UV contribuindo de forma positiva $(0,815)$ e de forma negativa o ozônio total ($0,738)$ e aerossóis $(-0,731)$. A maior correlação na segunda componente (CP2) representa a nebulosidade $(-0,866)$, na CP3 a radiação solar global $(0,765)$ e na CP4 a intensidade do vento ($0,639)$. Estas quatro componentes acumulam $83,1 \%$ da variação total das variáveis. Os valores estão destacados na Tabela 5.

Tabela 4. Matriz de Correlação entre as variáveis pesquisadas na cidade de Natal.

\begin{tabular}{l|r|r|r|r|r|r}
\hline \multicolumn{1}{c|}{ Variáveis } & Índice UV & $\begin{array}{c}\text { Ozônio } \\
\text { total }\end{array}$ & $\begin{array}{c}\text { AOD } \\
(\lambda=550 \mathrm{~nm})\end{array}$ & Vento & Nebulosidade & RSG \\
\hline Índice UV & 1,00 & & & & & \\
Ozônio total & $-0,49$ & 1,00 & & & & \\
Aerossóis (AOD) & $-0,48$ & 0,43 & 1,00 & & & \\
Vento & $-0,29$ & 0,22 & 0,23 & 1,00 & & \\
Nebulosidade & 0,03 & $-0,08$ & $-0,06$ & 0,20 & 1,00 & \\
RSG & 0,39 & $-0,21$ & $-0,25$ & $-0,24$ & $-0,04$ & 1,00 \\
\hline
\end{tabular}

Tabela 5. Correlações das variáveis e variação captada em cada componente resultante da ACP.

\begin{tabular}{l|r|r|r|r|r|r}
\hline Variável & CP1 & CP2 & CP3 & CP4 & CP5 & CP6 \\
\hline Índice UV & $\mathbf{0 , 8 1 5}$ & $-0,087$ & $-0,072$ & $-0,067$ & $-0,061$ & $-0,054$ \\
Ozônio total & $\mathbf{- 0 , 7 1 8}$ & 0,252 & 0,324 & 0,095 & $-0,473$ & 0,289 \\
Aerossóis (AOD) & $\mathbf{- 0 , 7 3 1}$ & 0,190 & 0,206 & 0,185 & 0,572 & 0,161 \\
Vento (intensidade) & $-0,528$ & $-0,531$ & 0,171 & $-\mathbf{0 , 6 3 9}$ & 0,045 & 0,014 \\
Nebulosidade & $-0,007$ & $-\mathbf{0 , 8 6 6}$ & 0,190 & 0,460 & $-0,041$ & 0,014 \\
Radiação solar global & 0,581 & 0,180 & $\mathbf{0 , 7 6 5}$ & $-0,056$ & 0,041 & $-0,199$ \\
\hline Variância acumulada & 0,389 & 0,584 & 0,717 & 0,831 & 0,925 & 1,00 \\
\hline
\end{tabular}

A contribuição das variáveis na CP1 e CP2 (58,4\% da variabilidade) foi representada no gráfico Biplot (Figuras 7A), onde cada ponto (número) representa os escores, ou seja, as observações projetadas nas componentes. O segundo gráfico Biplot (Figura 7B) não traz os escores e permite uma melhor visualização das setas indicadoras ao longo do eixo longitudinal. Estas setas indicam o sentido da máxima variação e devem ter comprimento proporcional à importância da variação, destacando-se nesse caso o Índice UV.

Os gráficos Biplot (Figura 7) mostraram que há concordância do índice UV em relação à RSG e oposição ao ozônio total, aerossóis (AOD) e vento. 

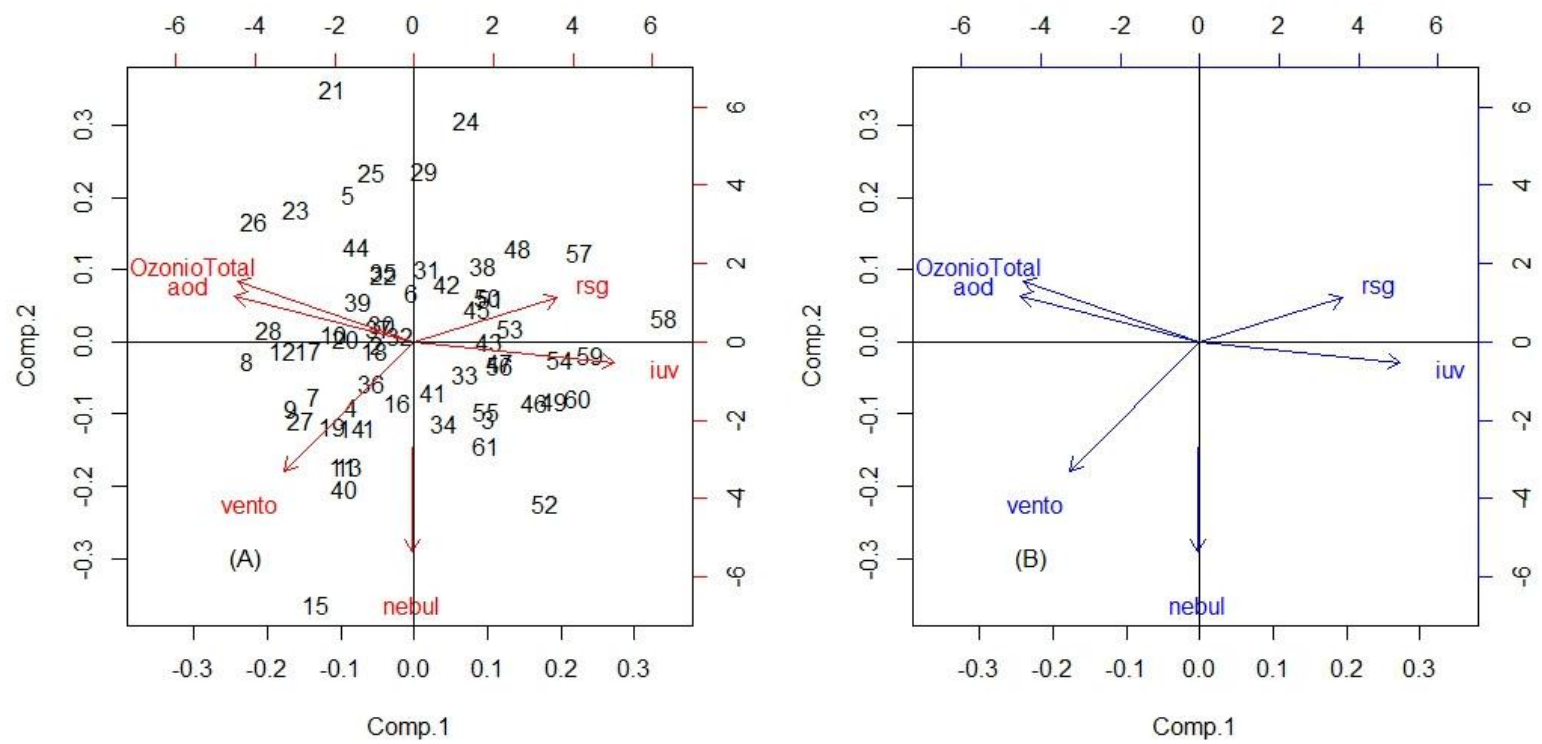

Figura 7- Gráfico Biplot da 1 e 2 componentes da ACP.

A ACP e gráfico Biplot mostraram a oposição entre o índice UV e variáveis ozônio total e aerossóis durante os meses de setembro e outubro, colaborando com as inferências construídas no estudo realizado sobre o EAP-UV.

\section{CONSIDERAÇÕES FINAIS.}

As medidas espectrais realizadas através do Radiômetro GUV indicaram que a intensidade de UVB e índice UV na cidade de Natal são maiores no 1 ㅇ semestre do ano em comparação ao 20 semestre, fato este associado aos maiores níveis de ozônio total no 2 o período do ano. Não houve redução nos níveis da UVA no 2 o semestre.

O índice UV apresenta média anual igual a 11, classificado como "extremo" pela WMO, sendo que sete meses do ano e aproximadamente $80 \%$ dos dias nos meses de verão atingem este índice.

A análise da variabilidade anual da UV e índice UV em relação às variáveis ozônio total, aerossóis, nebulosidade e radiação solar global indicou a existência em setembro e outubro do EAP-UV, que consiste de uma estabilização/redução na UV na superfície associada aos episódios de máximos valores anuais de ozônio total e maior presença de aerossóis, fato confirmado através da ACP e gráfico Biplot. O EAP-UV independe das condições do céu e consiste de uma característica da variabilidade anual da UV na cidade de Natal.

A investigação ampliou e aprofundou os conhecimentos da UV e sua relação com o ozônio total, aerossóis, radiação solar global e nebulosidade na cidade de Natal, inclusive divulgando o índice UV como um instrumento de prevenção e alerta sobre os perigos da radiação solar.

Os resultados são particularmente relevantes para a capital do RN, pois destacam os altos níveis da UV no verão e em praticamente todas as épocas do ano e sinalizam uma das causas que fazem desta cidade a capital no Nordeste do Brasil com o maior número de neoplasias de pele.

\section{AGRADECIMENTOS}


O presente trabalho foi realizado com apoio do Conselho Nacional de Desenvolvimento Científico e Tecnológico (CNPq), através do Doutorado Sanduíche - SWE/CsF (246611/2012-0) e projetos "ATMANTAR"-MCTI/PROANTAR/CNPq (520182/2006-5) e "A Atmosfera Antártica, Conexões e Impactos Ambientais na América do Sul", INCT-APA, MCTI/PROANTAR/CNPq (574018/2008-5).

Os autores agradecem a Profa Neusa Paes Leme, Engo Francisco Raimundo da Silva (INPE/CRN) e ao Prof. Luiz Guilherme M. de Souza (UFRN/LMHES) pelas orientações e gentileza ao fornecer os dados.

\section{REFERÊNCIAS}

[1] MADRONICH, S. UV radiation in the natural and perturbed atmosphere. In: Tevini, M (Ed). UVB Radiation and Ozone Depletion. London: Lewis Publishers. p. 17-69, 1993.

[2] LIOU, K. N. An Introduction to Atmospheric Radiation. Second Edition. Academic Press, USA, 2002.

[3] WHO. Global Solar Indice UV: A Practical Guide. World Health Organization, World Meteorological Organization (WMO), United Nations Environment Program (UNEP), and International Commission on Non-lonising Radiation Protection (ICNRP), 18 p. Geneva, 2002.

[4] WMO. Scientific assessment of ozone depletion, 2010. World Meteorological Organization, Report No. 47. Geneva, 2011.

[5] FIOLETOV, V. E., KERR, J. B., WARDLE, D. I. The relationship between total ozone and spectral UV irradiance from Brewer observations and its use for derivation of total ozone from UV measurements. Geophysical Research Letters, v.24, n. 23, p. 2997-3000, Canada, 1997.

[6] FREDERICK, J. E., LUBIN, D. Solar Ultraviolet Irradiance at Palmer Station, Antarctica. Ultraviolet Radiation in Antarctica: Measurements and Biological Effects. Antarctic Research Series, v. 62, p. 43-52, 1994.

[7] KIRCHHOFF, V. W. J. H. Ozônio e Radiação UV-B. Transtec Editorial, São José dos Campos, São Paulo, 1995.

[8] SABBURG, J., WONG, J. The effect of clouds on enhancing UVB irradiance at the earth's surface: a one year study. Geophysical Research Letters, 27, p. 3337-3340, 2000.

[9] HORVÁTH, M., BILITZKY, L., HUTTNER, J. Ozone. New York: Elsevier. 350 p, 1985.

[10] MCKENZIE, R.L. et al. Altitude effects on UV spectral irradiance deduced from measurements at Lauder, New Zealand, and at Mauna Loa Observatory, Hawaii. Journal of Geophysical Research, 106, p.22845-22860, 2001.

[11] VANICEK, K. et al. UV Indice for the Public. COST-713 Action. Luxemburgo: Office for official publications of the European Communities, 50, 2000.

[12] JACOBSON, Mark Z. Fundamentals of atmospheric modeling. Cambridge University Press, 2005.

[13] SEINFELD, J. H. Atmospheric chemistry and physics of air pollution. New York: John Wiley and Sons, 760p, 1985. 
[14] YAMASOE, M. A., Artaxo, P., Schafer, J., Eck, T. e Holben, B. Measurements and calculations of the influence of smoke particles on photosynthetically active radiation fluxes reaching the surface in the Amazon. Eos Trans. AGU, 81 (48), Fall Meet. Suppl., Abstract B61E-07, 2000.

[15] HERMAN, J.R et al. Changes in cloud and aerosol cover (1980-2006) from reflectivity time series using SeaWiFS, N7-TWHO, EP-TWHO, SBUV-2, and OMI radiance data. Journal of Geophysical Research, vol. 114, p. 01-21, 2009.

[16] CASICCIA, C., ZAMORANO, F. Erythemal irradiance at the Magellan's region and Antarctic ozone hole 1999-2005. Atmósfera, 21(1), 1-12, 2008.

[17] FAHEY, D.W., HEGGLIN M.I. (Coordinating Lead Authors). Twenty Questions and Answers about the Ozone Layer: 2010 Update, Scientific Assessment of Ozone Depletion: 2010, 72 pp., World Meteorological Organization, Geneva, Switzerland, 2011.

[18] HEGGLIN, M. I. SHEPHERD T. G. Large climate-induced changes in ultraviolet index and stratosphere-to-troposphere ozone flux. Nature Geoscience 2, p. 687-691, set, 2009.

[19] CORDERO, E. et al. Stratospheric Dynamics and the Transport of Ozone and Other Trace Gases. In: Chapter 6-Stratospheric Ozone: An Electronic Textbook, 2012 [Internet]. Disponível em: http://www.ccpo.odu.edu/ lizsmith/SEES/ozone/oz_class.htm

[20] SAHAI, Y., KIRCHHOFF, V., LEME, N. M. Total ozone trends in the tropics. Journal of Geophysical Research, v.105, n.D15, p. 19823-19823. EUA, 2000.

[21] MCKENZIE et al. Ozone depletion and climate change: impacts on UV radiation. Photochem. Photobiol. Sci., 10, 182-198, 2011.

[22] MCKENZIE, R.L. et al. Changes in biologically active ultraviolet radiation reaching the Earth's surface. Photochem Photobiol. Sci., v. 2, p. 1-4, 2003.

[23] HERMAN J.R. Global increase in UV irradiance during the past 30 years (1979-2008) estimated from satellite data. Journal of Geophysical Research, vol. 115, p. 01-15, 2010.

[24] LEE-TAYLOR, J., MADRONICH, S. Climatology of UV-A, UV-B, and Erythemal Radiation at the Earth's Surface, 1979-2000, National Center for Atmospheric Research Boulder, Colorado, 2007.

[25] INMET. Normais Climatológicas do Brasil 1961-1990. Brasília, DF, 2009.

[26] FURTADO, Edna Maria. A onda do turismo na cidade do sol: a reconfiguração urbana de Natal, 2005.

[27] INCA-Instituto Nacional de Câncer José Alencar Gomes da Silva, 2011. Estimativa 2012Incidência de Câncer no Brasil. Ministério da Saúde do Brasil.

[28] WEBB A.R., Holick, M. F. The role of sunlight in the cutaneous production of vitamin D3. Annu. Rev. Nutr., 8, p. 375-99, 1988.

[29] PARISI, A.F., GREEN, A., KIMLIN, M.G. Diffuse solar ultraviolet irradiation and implications for preventing human eye damage. Photochem. Photobiol., v. 73, n. 2, p. 135-139, 2001.

[30] DE GRUIJL, F. R. UV-induced immunosuppression in the balance. Photochem. Photobiol. 84, p. 2-9, 2008.

[31] MADRONICH, S., GRUIIL, F.R. Skin cancer and UV radiation. Nature, 366, p. 23-28, 1993. 
[32] DIFFEY, B.L. The consistency of studies of ultraviolet erythema in normal human skin. Physics in Medicine and Biology, 27, p. 715-720, 1982.

[33] DIFFEY, B.L. Solar ultraviolet radiation effects on biological systems. Physics in Medicine and Biology, 36(3), p. 299-328, 1991.

[34] LONGSTRETH, J. et al. Health risks. J.Photoch. Photobio. B,v. 46, p. 20-39, 1998.

[35] CORRÊA, M. P. Índice ultravioleta: avaliações e aplicações. Tese (Doutorado Ciênciasmeteorologia) Instituto de Astronomia, Geofísica e Ciências Atmosféricas, USP, São Paulo, 2003.

[36] ARAúJO, V. M. D., 1996. Parâmetros de conforto térmico para usuários de edificações escolares no litoral nordestino brasileiro. Tese de doutorado. FAUSP. São Paulo.

[37] PEREIRA, E. B. et al. Atlas brasileiro de energia solar, INPE, São José dos Campos, Brasil. ISBN 978-85-17-00030-0, 2006.

[38] IBGE. Mapa de Clima do Brasil. [Internet], 2013. Disponível em $\mathrm{ftp}$ //geoftp.ibge.gov.br/mapas_tematicos/mapas_murais/. Acesso: Novembro-2013

[39] NEVES, J.A. Um índice de susceptibilidade ao fenômeno da seca para o semiárido nordestino. Tese de Doutorado, Universidade Federal de Pernambuco, UFPE, Recife, 2010.

[40] NOBRE, P., MELO, A. B. C. Variabilidade climática intrasazonal sobre o Nordeste do Brasil em 1998-2000. Revista Climanálise, ano 2, n.1, 2004.

[41] LOPO, A. B., MATA, M. V. M., ANDRADE, R. L., SILVA, C. M. S. Ciclo diário de precipitação sobre a cidade de Natal-RN. Congresso Brasileiro de Meteorologia, SBMET, Belém, Brasil, 2010.

[42] MOTTA, Adauto Gouveia. O clima de Natal. Natal: Foco,[s/d], 2004.

[43] NOBRE, C. A., MOLION, L. C. B. The climatology of drought and drought prediction. In: PARRY, T. R.; CARTER, R.; KONJIN, N. T. The impact of variations on agriculture. Volume 2: Assessments in Semi-arid Regions. Dordrech: Kluwer, p. 305-323, 1988.

[44] IBGE. Estimativa Populacional 2013, [Internet], 2013. Disponível em:

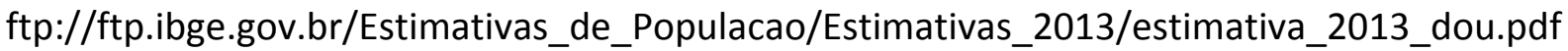

[45] MCKINLAY, A., F. DIFFEY, B. L. A reference action spectrum for ultraviolet-induced erythema in human skin. In: Passchler and Bosnajokovic ed. Human exposure to ultraviolet radiation: Risks and regulations. Amsterdã, Elsevier, 1987.

[46] Biospherical Instruments. Application note: GUV “Diffey Dose" calculations. URL<http://www.biospherical.com>.

[47] GES DISC-Database of NASA-Goddard Earth Sciences Data and Information Services Center [Internet]. EUA, 2013. Disponível em: http://avdc.gsfc.nasa.gov/

[48] LEPTOUKH, G. et al. NASA GES DISC on-line visualization and analysis system for gridded remote sensing data. In: Leptoukh, S. Berrick, H. Rui, Z. Liu, T. Zhu, S. Shen//Proc. of the 31th International Symposium of Remote Sensing of the Environment, 2005.

[49] SMITH, Jacqueline (Ed.). The Facts on File dictionary of weather and climate. Infobase Publishing, 2009. 
[50] INPE/CRN/LAVAT-Instituto Nacional de Pesquisas Espaciais/Centro Regional do Nordeste. Laboratório de Variáveis Ambientais Tropicais. [Internet]. BRASIL, 2013. Disponível em: http:// http://www.crn2.inpe.br/lavat/

[51] INMET/BDMEP. [Internet]. BRASIL, 2013. Disponível em: http://www.inmet.gov.br/projetos/rede/pesquisa/.

[52] INPE/CPTEC/SISAM, 2013. [Internet]. BRASIL, 2013. Disponível em: http://sisam.cptec.inpe.br.

[53] JOHNSON, R. A., WICHERN, D., W. Applied Multivariate Statistical Analysis, Fifth Edition, cp. 1 - Aspects of Multivariate Analysis, cp. 2 - Matrix Algebra and Random Vectors, cp. 8 - Principal Components, 2002.

[54] MINGOTI, S. A. Análise de dados através de Métodos de Estatística Multivariados. UFMG, 2005.

[55] WILKS, S. D. Statistical Methods in the Atmospheric Sciences. Academic Press, San Diego, 2a ed, 2006.

[56] R Development Core Team. R: A language and environment for statistical computing. R Foundation for Statistical Computing, 2002. Vienna, Austria. ISBN 3-900051-07-0. [Internet]. Austria, 2013. Disponível em: http://www.r-project.org/

[57] GABRIEL, K. R. The biplot graphic display of matrices with application to principal component analysis. Biometrika, Oxford, v.58, no 3, p. 453-467, 1971.

[58] MARÍN FERNÁNDEZ, María José et al. Estudio de la irradiancia solar ultravioleta B y eritemática en la Comunidad Valenciana. 2007.

[59] SILVA, F. R. Estudo da Radiação Ultravioleta na cidade de Natal-RN. Dissertação (Mestrado Engenharia Mecânica) - UFRN, Natal-RN, 2008.

[60] VAREJÃO, M. A. Meteorologia e Climatologia. Versão digital no 02, Recife, 2006.

[61] ROY, C. R., GIES, H. P., TOOMEY, S. Monitoring UV-B at the earth's surface. Australian Meteorological Magazine, v. 46, no 3, p. 203-210, 1997.

[62] CORRÊA, M.P., DUBUISSON, P., PLANA-FATTORI, A. An Overview of the Ultraviolet Index and the Skin Cancer Cases in Brazil. Photochemistry and Photobiology, 78(1): p. 49-54, 2003.

[63] IALONGO, I. Comparison of total ozone and erythemal UV data from OMI with ground-based measurements at Rome station. Atmos. Chem. Phys., 8, p. 3283-3289, 2008.

[64] KIRCHHOFF, V. W. J. H et al. Equatorial ozone characteristics as measured at Natal $\left(5.9^{\circ} \mathrm{S}\right.$, 35.2 ${ }^{\circ}$ W). Journal of Geophysical Research. Volume 88, Issue C11, p. 6812-6818, 1983.

[65] OLIVEIRA, H. S. M., SILVA, F. R., MARÍTIMO, G., LEME, N. M. P. Análise da coluna de ozônio em Natal-RN. II Simpósio Brasileiro de Geofísica Espacial e Astronomia, UFCG, Brasil, 2008.

[66] CORRÊA, M.P., CEBALLOS, J. C., PLANA-FATTORI, A. Uma análise das variações do Índice Ultravioleta em relação às observações de conteúdo de ozônio e da espessura óptica dos aerossóis sobre a cidade de São Paulo. Revista Brasileira de Meteorologia, v.21, no 1, p. 24-32, São Paulo, 2006. 
[67] CORRÊA, M.P., CEBALLOS, J. C. Solar Ultraviolet Radiation Measurements in One of the Most Populous Cities of the World: Aspects Related to Skin Cancer Cases and Vitamin D Availability. Photochemistry and Photobiology, V. 86, p. 438-444, 2010.

[68] SILVA, A. A. A Espessura óptica de aerossóis na banda do UV-B. Tese de Doutorado em Geofísica Espacial-INPE, São Jose dos Campos, 2002. 